\title{
Gender Difference in Spirometric Lung Functions in Chronic Obstructive Pulmonary Disease Patients Attending Rims Hospital Out-Patient Department.
}

\author{
A. Jannie Shimray, W. Kanan, S.N. Naithok Jamatia, Sharon Roel, L.Bellamy \\ Kom, Franc Oumanath, Merrycka A. Sangma, H. Hungyo
}

I. Introduction

Chronic Obstructive Pulmonary Disease (COPD) is a preventable and treatable disease with some significant extra pulmonary effects that may contribute to the severity in individual patients. Its pulmonary component is characterized by airflow limitation that is not fully reversible. The airflow obstruction is usually both progressive and associated with an abnormal inflammatory response of the lungs to noxious particles and gas. [1] It is a major cause of chronic morbidity and mortality throughout the world and is currently the fourth leading cause of death.[2] Contemporarily, the diagnosis and classification of chronic obstructive pulmonary disease (COPD) is based on spirometric assessment only.[3] Based on studies of pulmonary function, it has recently been suggested that females may be more susceptible than males to the deleterious effects of smoking with regard to development of COPD.[4,5] Several studies have demonstrated greater susceptibility among women to develop COPD by demonstrating larger reductions in $\mathrm{FEV}_{1}$, after adjustment for smoking intensity, among female smokers compared with male smokers. The aim of the present study was to determine whether gender difference is present in COPD and indirectly to determine if there is a difference in effect of smoking on different gender, using spirometric lung function.

\section{Material and Methods}

A cross sectional study constituting 50 COPD patients ( 25 women and 25 men) between the age $40-65$ years of age who attended Respiratory Medicine OPD (Out Patient Department) of the Regional Institute of Medical Sciences (RIMS), Imphal were included in the study. This preliminary study was conducted in the Department of Physiology, RIMS. Lung function was measured with Computerised Spirometer Helios 701(Recorders and Medicare System, Chandigarh). FVC, $\mathrm{FEV}_{1}, \mathrm{FEV}_{1} \%$ predicted, $\mathrm{FEV}_{1} / \mathrm{FVC}, \mathrm{FEV}_{1} / \mathrm{FVC} \%$ and $\mathrm{FEF}_{25-75}$ were recorded and values in men and women subjects were compared. Statistical analysis was performed using SPSS version 16.0. Independent t-tests was used. Pack years was calculated from the average number of cigarettes smoked per day in a year, one pack year being smoking of 20 cigarettes per day for one year.

Calculating Pack Years Of Smoking

20 cigarettes $=1$ packet

Pack years of smoking $=($ Number of cigarettes smoked per day $\mathrm{X}$ no of years of Smoking)/ 20

For example, a smoker of 10 cigarettes a day who has smoked for 15 years would have smoked:

$(10 \mathrm{X} 15) / 20=7.5$ pack years.

Quantification of pack-years smoked is important in clinical care, where degree of tobacco exposure is correlated to risk of disease. ${ }^{[6]}$ Pack years of smoking being a key predictive factor in the development of COPD is well supported by numerous studies. ${ }^{[7]}$

Institutional Ethics Committee approved the research study and patients gave their informed consent to participate in the study.

\section{Results}

Demographic description of the total study group is shown in Table 1. Fifty patients (mean age $57.19 \pm$ $11.01 ; \mathrm{M} / \mathrm{F}=25 / 25$ ) were evaluated. Smoking history of the subjects showed $14.58 \%$ to be former smokers and $85.2 \%$ current smokers. 
Gender Difference in Spirometric Lung Functions in Copd Patients Attending Rims Hospital Out-

TABLE1: Patient characteristic Description

\begin{tabular}{|l|c|c|c|c|}
\hline & & TOTAL & MALE & FEMALE \\
\hline \multirow{2}{*}{ Age in years(Mean \pm SD) } & & $57.19 \pm 11.01$ & $57 \pm 10.70$ & $59.33 \pm 6.60$ \\
\hline \multirow{2}{*}{ Male/Female Ratio } & $25 / 20$ & & & \\
\hline \multirow{2}{*}{ Smoking history N (\%) } & Ex-smokers & $41(85.2)$ & 21 & 20 \\
\cline { 2 - 5 } & Current smokers & $9(14.58)$ & 4 & 5 \\
\hline \multirow{2}{*}{ Pack year (Mean \pm SD) } & & $27.70 \pm 12.24$ & & \\
\hline
\end{tabular}

TABLE 2: Mean \pm SD of flow parameters according to gender

\begin{tabular}{|l|c|c|c|}
\hline \multirow{2}{*}{ Parameter } & \multicolumn{2}{|c|}{ Gender (Mean \pm SD) } & \multirow{2}{*}{ p-value } \\
\cline { 2 - 3 } & $\begin{array}{c}\text { Male } \\
\mathbf{( N = 2 5 )}\end{array}$ & $\begin{array}{c}\text { Female } \\
\mathbf{( N = 2 5 )}\end{array}$ & \\
\hline $\mathrm{FVC}(\mathrm{L})$ & $1.81 \pm 0.68$ & $1.25 \pm 0.59$ & $<0.005$ \\
\hline $\mathrm{FEV}_{1}(\mathrm{~L})$ & $1.64 \pm 0.70$ & $1.02 \pm 0.53$ & $<0.005$ \\
\hline $\mathrm{FEV}_{1} \%$ pred & $71.96 \pm 25.16$ & $63.1 \pm 27.54$ & $>0.005$ \\
\hline $\mathrm{FEV}_{1} / \mathrm{FVC} \%$ & $88.87 \pm 11.91$ & $83.79 \pm 13.85$ & $>0.005$ \\
\hline $\mathrm{FEF}_{25-75}(\mathrm{~L})$ & $2.23 \pm 1.29$ & $1.22 \pm 0.89$ & $<0.005$ \\
\hline
\end{tabular}

The distribution of mean \pm SD of flow parameters in males and females is shown in table 2. All values are higher in males as compared to females and this finding is highly significant for $\mathrm{FVC}, \mathrm{FEV}_{1}$, and $\mathrm{FEF}_{25-75}$.

Table 3: Comparison of mean \pm S.D of $\mathrm{FEV}_{1} / \mathrm{FVC}$ between male and female patients

\begin{tabular}{|c|c|c|c|}
\hline Smoking pack years & Male(n=25) & Female(n=25) & p- value \\
\hline $1-9$ & $1.06 \pm 0.21$ & $0.98 \pm 0.25$ & $<0.005$ \\
\hline$>9-19$ & $1.01 \pm 0.20$ & $0.74 \pm 0.11$ & $<0.005$ \\
\hline$>19$ & $0.75 \pm 0.05$ & $0.62 \pm 0.12$ & $<0.005$ \\
\hline
\end{tabular}

TABLE 4: Mean \pm S.D of FEV $1 \%$ predicted between male and female patients

\begin{tabular}{|c|c|c|c|}
\hline Smoking pack years & Male(n=25) & Female(n=25) & p value \\
\hline $1-9$ & $79.57 \pm 17$ & $75.9 \pm 15$ & $>0.005$ \\
\hline$>9-19$ & $76 \pm 30$ & $66.6 \pm 35$ & $>0.005$ \\
\hline$>19$ & $48 \pm 15$ & $48 \pm 21.5$ & $>0.005$ \\
\hline
\end{tabular}

Table 3 shows significantly higher values of $\mathrm{FEV}_{1} / \mathrm{FVC}$ in male subjects as compared to female in all categories of smoking packing years over and above the finding of progressive decline in the ratio as the smoking pack years increases. The finding is similar in table 4 but without significance.

\section{Discussion}

With increase in the smoking pack years there was a decrease in $\mathrm{FEV}_{1}, \mathrm{FEV}_{1} \%$ predicted and $\mathrm{FEV}_{1} / \mathrm{FVC}$ values in both males and females. Mean $\mathrm{FEV}_{1} / \mathrm{FVC}$ values in each of the smoking pack years category was found to be significantly decreased in females, along with decrease in mean FVC, FEV $\mathrm{F}_{1}$ and $\mathrm{FEF}_{25-75}$ suggesting a relationship between loss of lung function and gender in this study. Females have lower levels of $\mathrm{FEV}_{1}$ and $\mathrm{FEV}_{1} \%$ of predicted as compared to male subjects. Similar to the findings of the present study $\mathrm{Xu} \mathrm{X}$ et al ${ }^{[8]}$ also found significantly greater rates of $\mathrm{FEV}_{1}$ decline among female smokers than among male smokers in their study. Possible explanations for this include differences in lung geometry between the sexes, because females, on average, would be expected to have smaller airways and smaller lung volumes than males. ${ }^{[9]}$ Prescott and colleagues demonstrated that female smokers had greater reductions in $\mathrm{FEV}_{1}$ than males at comparable levels of smoking intensity; they also found increased risk for hospitalization due to COPD in female smokers, after adjusting for smoking intensity. ${ }^{[10]}$ Hormonal differences ${ }^{[11]}$ and a higher susceptibility of females to the deleterious effects of smoking than males ${ }^{[5]}$ are other factors to be considered. Interaction of genetic factors with cigarette smoking contributing to the development of COPD has been proposed by Silverman E K et al. ${ }^{[12]}$ 


\section{Conclusion}

Mean $\mathrm{FEV}_{1}, \mathrm{FEV}_{1} \%$ predicted and $\mathrm{FEV}_{1} / \mathrm{FVC}$ values are found to be higher in males in each of the smoking pack years category suggesting that females seem to suffer more severe disease as compared to their male counterparts which seems to agree with several other studies. However the present study is limited by relatively smaller number of patients and perhaps a larger sample size would yield more significant results.

\section{References}

[1]. Pauwels RA, Buist AS, Calverley PM, Jenkins CR, Hurd SS. Global strategy for the diagnosis, management, and prevention of chronic obstructive pulmonary disease. NHLBI/WHO Global Initiative for Chronic Obstructive Lung Disease (GOLD) Workshop summary. Am J Respir Crit Care Med 2001;163(5):1256-1276.

[2]. World Health Report. World Health Organisation. Geneva 2000.

[3]. Hoogendoorn M, Feenstra TL, Schermer TR, Hesselink AE, Rutten-van Molken MP. Severity distribution of chronic obstructive pulmonary disease (COPD) in Dutch general practice. Respir Med 2006;100:83-6.

[4]. $\quad \mathrm{Xu} X, \mathrm{Li}$ B, Wang L. Gender difference in smoking effects on adult pulmonary function. Eur Respir J 1994; 7: 477-483.

[5]. Chen Y, Home SL, Dosman JA. Increased susceptibility to lung dysfunction in female smokers. Am Rev Respir Dis 1991; 143: 1224-1230.

[6]. World Health Organization (2008), WHO Report on the Global Tobacco Epidemic 2008: The MPOWER Package.

[7]. Anon. Diagnosing obstructive airways disease. Bandolier. Aug 2000; 78-2.

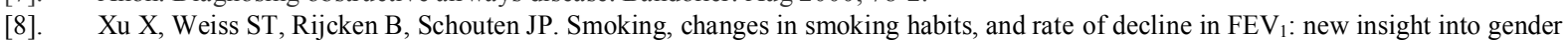
differences. Eur Respir J 1994; 7: 1056-61.

[9]. Brooks LJ, Byard PJ, Helms RC, Fouke JM, Strohl KP. Relationship between lung volume and tracheal area as assessed by acoustic reflection. J Appl Physiol 1988; 64:1050-4.

[10]. Prescott E, Bjerg AM, Andersen PK, Lange P, Vestbo J. Gender difference in smoking effects on lung function and risk of hospitalization for COPD: results from a Danish longitudinal population study. Eur Respir J 1997;10:822-827.

[11]. Celedon JC, Speizer FE, Drazen JM, Weiss ST, Campbell EJ, Carey VJ, et al. Bronchodilator responsiveness and serum total IgE levels in families of probands with severe early-onset COPD. Eur Respir J 1999; 14: 1009-14.

[12]. 12.Silverman E K, Weiss S T, Drazen J M, Chapman H A, Carey V, Campbell EJ, et al. Gender-related differences in severe, earlyonset Chronic Obstructive Pulmonary Disease .Am J Respir Crit Care Med Vol 162. pp 2152-2158, 2000. 